\title{
DESIGN SOCIAL E PARTICIPATIVO: UM RELATO DE EXPERIÊNCIA PARA VALORIZAÇÃO DO ARTESANATO DO DENDÊ
}

Suzana Angélica da Silva Mascarenhas Pina

Universidade Federal da Bahia

pina.suzana@gmail.com

Adriana Sousa Fernandes da Silva

Universidade Federal da Bahia

drinandes@hotmail.com

Ana Amélia Campos dos Anjos

Universidade Federal da Bahia

melcamposdes@gmail.com

Ana Carolina de Lima Sarmento

Universidade Federal da Bahia

carol_sarmento@hotmail.com

Andrea de Matos Machado

Universidade Federal da Bahia

dea.cad@gmail.com
Carina Santos Silveira

Universidade Federal da Bahia

carinassilveira@gmail.com

Mariana Rosario Marin

Universidade Federal da Bahia

marianarosariomarin@gmail.com

Naiara Gomes de Oliveira

Universidade Federal da Bahia

naidesign@hotmail.com

Ana Beatriz Simon Factum

Universidade Federal da Bahia /

Universidade do Estado da Bahia

biasimon@gmail.com

Paulo Fernando de Almeida Souza

Universidade Federal da Bahia

paulodesign@gmail.com

Resumo: Com a proposta de fomentar o Design Social na Bahia, mediando pesquisa etnográfica, design e valorização da identidade cultural, este trabalho apresenta a cultura da Comunidade do Artesanato do Dendê, localizada na Estrada do Coco, Camaçari-BA, desde a coleta do material até a comercialização dos produtos. Expõe a história do grupo para conhecimento de toda comunidade local e sociedade, proporcionando a visualização do valor material e imaterial do artesanato para a localidade e busca também reforçar a importância da sua continuidade, promovendo o estímulo à autoestima e valorização dos artesãos. Como resultado, criou-se um instrumento de diálogo com a sociedade civil e governo para incentivo à continuidade da cultura do artesanato da palha do dendê, com a produção de um documentário, o qual foi apresentado para a comunidade e entregue em mídia digital para os líderes e representantes de cada família envolvida no processo. Para a prática projetual foi utilizada a metodologia colaborativa onde os integrantes da equipe de projeto, bem como os membros da comunidade do dendê, foram agentes diretamente envolvidos em cada fase do processo. Neste trabalho, o designer tornou-se um dos agentes no processo de transformação da comunidade, abertos a novos conceitos e atitudes, trazendo uma abordagem metodológica colaborativa e contribuindo na prática com os conceitos do design para 
inovação social, abrangendo a sensibilidade artística e cultural que poderá ser reproduzida em outras comunidades emergentes.

Palavras-chave: Vídeo-documentário, Design para Inovação Social, Identidade cultural, Artesanato Dendê.

\begin{abstract}
In order to stimulate Social Design in Bahia, by ethnographic research, design and improvement of cultural identity, this work presents the craftwork culture of Palm Crafts community, located in the Coconut Road, Camaçari-BA, since the collection of the material until the marketing of products. It exposes the history of the group to the entire local community knowledge and society, providing viewing of the tangible and intangible value of the craftwork to the location and seeks to reinforce the importance of continuity, promoting the encouragement of self-esteem and appreciation of artisans. As a result, we created a tool, as one way to discuss with civil society and with the government, to encourage the continuity of craft culture straw palm culture, by producing a documentary, which was shown to the community and delivered on digital media to leaders and representatives of each family involved in the process. To the design practice was used collaborative methodology in which the team members of the project and members of the palm of the community were directly involved in each stage of the process. In this work, the designer has become one of the agents in the community transformation process, open to new concepts and attitudes, bringing a collaborative methodology and contributing in practice with the concepts of design for social innovation, covering the artistic sensibility and cultural that may be reproduced in other emerging communities.
\end{abstract}

Keyword: Video documentary, Design for Social Innovation, Cultural identity, Dende craftwork.

\title{
1. INTRODUÇÃO
}

Devido à necessidade de aperfeiçoar os sistemas culturais e sociais, percebendo as carências tanto das pessoas quanto da região em que vivem, Manzini (2008) afirma que um profissional capaz de contribuir de forma significativa com as transformações culturais é o designer, promovendo o desenvolvimento de projetos e meios sustentáveis que auxiliem as pessoas a melhorar seu contexto físico e social.

Neste caso, o design para inovação social (BECKMAN e BARRY, 2007; MULGAN, 2007; THE YOUNG FOUNDATION, 2012; MANZINI, 2014) favorece a integração entre a pesquisa etnográfica, o design e a valorização da identidade cultural, tornando o designer um dos agentes no processo de transformação da sociedade, abertos a novos conceitos e atitudes, com uma abordagem metodológica colaborativa.

Para tanto este artigo apresenta um projeto desenvolvido em uma disciplina de Doutorado sobre Design para Inovação Social do Programa de Pós-Graduação da 
Universidade Federal da Bahia - UFBA, junto à comunidade do Artesanato do Dendê, localizada na Estrada do Coco, BA-099, s/n Catu de Abrantes, Camaçari-BA.

Com o objetivo de criar um instrumento de comunicação, com a sociedade civil e governo, para valorizar a continuidade e o fortalecimento da cultura do artesanato da palha do dendê na região de Camaçari, optou-se de forma participativa e colaborativa pela produção de um vídeo-documentário, com o intuito de promover valorização de identidade e autoestima da comunidade em questão.

Os objetivos específicos contemplam as seguintes ações:

a) Produzir um documentário utilizando o método colaborativo;

b) Apresentar a cultura do artesanato do dendê, desde a coleta do material até a comercialização dos produtos;

c) Expor a história do grupo para conhecimento de toda comunidade local e sociedade;

d) Proporcionar a visualização do valor material e imaterial do artesanato para a localidade, reforçando a importância da sua continuidade, promovendo o estímulo à autoestima e valorização dos artesãos.

Sob este viés, o design para inovação social e o design participativo surgem como ferramentas para promover valores culturais, sem perder a sensibilidade do modo de fazer local, preservando as técnicas de artesanato da comunidade e agregando valor ao reconhecimento da sua importância.

\section{DESIGN PARA INOVAÇÃO SOCIAL E DESIGN PARTICIPATIVO}

O design para inovação social busca solucionar problemas e agregar valor a bens e serviços considerando a cultura e as necessidades das pessoas envolvidas em uma comunidade. Principalmente quando se trata de comunidades criativas que obtêm seu sustento por meio do artesanato.

Segundo Margolin e Margolin (2004), o contexto do modelo social do Design objetiva não somente satisfazer as necessidades humanas, mas principalmente contribuir para a transformação social, o que difere dos modelos de projetos desenvolvidos habitualmente no campo do design com foco na indústria e no mercado. Esta ideologia não deve ser vista como uma atividade ligada a doações e caridade. Não se trata de trabalho voluntário e deve ser encarado como uma contribuição profissional dedicada ao desenvolvimento da economia local, respeitando as relações com o meio ambiente.

Para tanto, em entrevista ao editorial Brasileiros (BORGES, 2012), a crítica e curadora do design brasileiro Adélia Borges reforça esse olhar, expondo seus pensamentos sobre o artesanato no Brasil, com sua percepção em relação ao investimento na produção artesanal, salientando que é importante o desenvolvimento e, o alcance dos mercados consumidores "[...] em condições de dignidade para o elo inicial da produção, ou seja, o artesão". (BORGES, 2012, p.95). Reforça que em várias regiões está progredindo um empreendedorismo sustentado em pequenas empresas familiares, destacando marcas de inovação, que implicam na apropriação inteligente do design ao sistema produtivo. Ainda detalha a sensibilidade destacada nesses objetos artesanais, declarando que os objetos artesanais: 
[...] nos contam de um lugar preciso, onde foram feitos por pessoas concretas. São honestos, confiáveis. Transmitem cultura, memória. Trazem um sentido de pertencimento. Por tudo isso, podem tocar - e o uso do verbo tocar não é fortuito - o nosso coração, a nossa alma. (BORGES apud VACARO, 2013).

Borges (2010, p. 47) considera que nas produções orientadas pelo design, ocorrem conexões emocionais entre os objetos e seus usuários, tornando-os melhor cuidados e conservados. Ainda afirma que, "[...] projetos que entendem o contexto cultural em que o objeto vai se inserir, em geral trazem expressos um respeito ao ser humano e, dessa forma, podem proporcionar vínculos simbólicos mais sólidos com as pessoas." (BORGES, 2010, p. 47). A autora enfatiza que algumas estratégias de design (identidade, embalagens, catálogos), atualmente mais empregadas em médias e grandes empresas, podem ser adotadas por pequenos empreendedores, inclusive com elementos artesanais e sociais bem destacados.

Nesse contexto, o design para inovação social, prima por uma abordagem de metodologia participativa, onde é fundamental que todos os envolvidos contribuam e participem em condições igualitárias na construção dos pensamentos e soluções para os problemas identificados.

Quanto às situações de como lidar com as comunidades criativas e as inovações sociais, Manzini (2008, p. 83) expõe de forma crítica que "[...] a criatividade e as atitudes colaborativas não podem, por definição, ser impostas". Percebe-se que as comunidades criativas são organizações sociais muito delicadas e cada intervenção externa coloca seu equilíbrio em risco. Esta situação é vivida em ambientes em que a comunidade deve ter a liberdade de decidir o caminho a ser seguido e promover um resultado favorável para todos que estão inseridos neste contexto. Isso converge para uma mudança de cultura, que envolve conjunturas diferentes e geram desdobramentos de maior proporção, podendo, em algumas situações, não abarcar soluções holísticas em prol do crescimento dos negócios. Ademais, como aponta Manzini (2014), "[...] O papel do design em processos de inovação social é ativar novas relações sociais, por meio de iniciativas de design. [...] fazer as coisas acontecerem. " (Manzini, 2014, p. 65-66).

Neste caso, pode-se aplicar o conceito do Metaprojeto, conforme afirmação de Moraes (2006, p. 1):

[algo] que vai além do projeto, que transcende o ato projetual, trata-se de
uma reflexão crítica e reflexiva sobre o próprio projeto a partir de um
cenário aonde se destacam os fatores produtivos, tecnológicos,
mercadológicos, materiais, ambientais, socioculturais e estético-formais,
tendo como base, análises e reflexões anteriormente realizadas através de
prévios e estratégicos recolhimentos de dados.

Esse conceito pode ser entendido como um "[...] campo estratégico e avançado [...]" (MORAES, 2006) diante do cenário atual, e desenvolve-se por meio de uma exploração de possíveis cenários, os quais podem sofrer transformações de modo a agregar valor e qualidade aos resultados do projeto, beneficiando todos os interessados, inclusive a atuação no processo de criação orientado pelo design.

Portanto, o trabalho apresenta uma ênfase no atendimento às expectativas institucional e da comunidade atendida por intermédio de uma cooperação multifuncional (co-criação), de modo que a construção do projeto foi feita de maneira 
colaborativa, pois é importante salientar que "[...] inovar significa compreender as dinâmicas socioculturais que podem conduzir a propor significados e linguagens" (DESERTI, 2011). E a linguagem proposta em consenso com o objeto de estudo, propõe valorizar culturalmente a comunidade do Dendê.

Com relação à metodologia e ferramentas de criação, o autor Martins (2008) faz uma reflexão sobre como explorar os conteúdos simbólicos, de modo a conduzir a construção de cenários por novos caminhos e propostas mais sensíveis resultantes do processo de criatividade. Martins (2008, p. 1) expõe que nos estudos desenvolvidos, a prática do design pode ser "[...] mais desprendida dos métodos e das técnicas convencionais e, portanto, mais afinada com as emoções e os sentidos [...]", tendo como foco o processo do design. Com base na afirmação, percebe-se que existe uma preocupação em valorizar os aspectos mais subjetivos no processo de criação, oferecendo outras possibilidades de inspiração mais desprendidas dos conceitos, teorias e métodos convencionais já referenciados por autores como Baxter (2001) e Rozenfeld et al., (2006).

Vale salientar que não é possível atribuir elementos simbólicos sem munir-se de pesquisas e métodos exploratórios que conduzam aos objetivos da proposta, pois a vivência, a cultura e as tradições contribuem com elementos primários no processo criativo. Para tanto Martins (2008, p. 02) afirma que "trata-se de um processo de familiarização com a sensibilidade do humano para transitar por um universo de informações que são reais, verdadeiras, mas que não estão ao alcance dos olhos".

Com base nesses argumentos, Martins (2008, p.02) reforça que, "[...] o designer poderá atuar como tradutor de anseios secretos", pois o "[...] verdadeiro sentido deve ser buscado pelo próprio designer". Com isso destaca a importância de traduzir e interpretar as informações que não são visíveis, mas podem ser sentidas, além de trazer uma carga emocional aliada às situações vividas. Portanto, existe a necessidade de explorar e exercitar esse pensamento no designer (MARTINS, 2008). Esse pensamento colabora com novas experiências que podem ser vividas, agregando novos conhecimentos e valor às suas criações, podendo gerar conceitos mais densos de elementos simbólicos que transmitem mais que uma mensagem linear, mas que possam transmitir sensações e emoções.

Neste sentido, foi concebido o documentário sobre o Artesanato do Dendê, com a proposta de reforçar a importância da sua continuidade, promovendo a autoestima e valorização dos artesãos.

\subsection{Mapeamento dos problemas e perspectivas futuras}

A comunidade do Artesanato do Dendê está localizada na Estrada do Coco, BA099, s/n - Catu de Abrantes, Camaçari-BA. Hoje, a Comunidade do Dendê produz e vende seu artesanato - mobiliário e artefatos de decoração, às margens da rodovia. Sendo que por este local passará uma Via Metropolitana e com a construção da nova via, o grupo de artesãos será remanejado para o outro lado da pista, em local planejado por instituições governamentais. Atualmente, esse ponto de venda dos produtos fabricados pelos artesãos é composto por 23 boxes pertencentes a 23 famílias, formadas por produtores da região, cuja maioria dos membros de cada família dedica-se exclusivamente a esta atividade, obtendo seu sustento por meio desse comércio. 
A situação de mudança para outro local também traz a importância de registrar o local onde tudo começou, mas a valorização e preservação do trabalho da comunidade do Artesanato do Dendê tem destaque neste trabalho, pois a vivência, a cultura e as tradições contribuíram com o processo criativo e colaboraram com o desenvolvimento de novos produtos e na visibilidade de novos mercados.

As famílias que sobrevivem do artesanato do dendê relataram situações do dia a dia, o tempo de atividade, problemas que enfrentam, tanto para conseguir os insumos para confeç̧ão dos artefatos, como para dar continuidade a essa cultura, havendo a necessidade de motivar os jovens da comunidade a investirem seu tempo no aprendizado desse ofício.

Por meio de uma roda de conversa ${ }^{1}$, foi possível realizar o mapeamento do cenário atual dos artesãos e suas principais queixas. A maioria dos artesãos possui mais de 10 anos de história no artesanato, alguns dos quais entre 20 a 26 anos nesta atividade. Muitos relataram o sentimento de incerteza e ao mesmo tempo de esperança vislumbrados diante da proposta de mudança do local de venda dos produtos. Outro problema encontrado na comunidade do artesanato refere-se à dificuldade na aquisição de matéria-prima, uma vez que a palha do dendê se encontra cada vez mais escassa.

Os principais produtos concebidos na comunidade (Figura 1) são fabricados com a palha do dendê, sendo hoje bastante rara nas imediações da comunidade, devido à grande expansão imobiliária na região. Com isso, o avanço do desmatamento é um grande problema para a coleta de matéria-prima, provocando uma redução do fornecimento das palhas. Além disso, existe a dificuldade de trabalhar com a madeira utilizada para estrutura dos artefatos e móveis, a qual é proibida por lei (Pau Paraíba), sendo necessário um estudo para adotar uma nova espécie que a substitua.

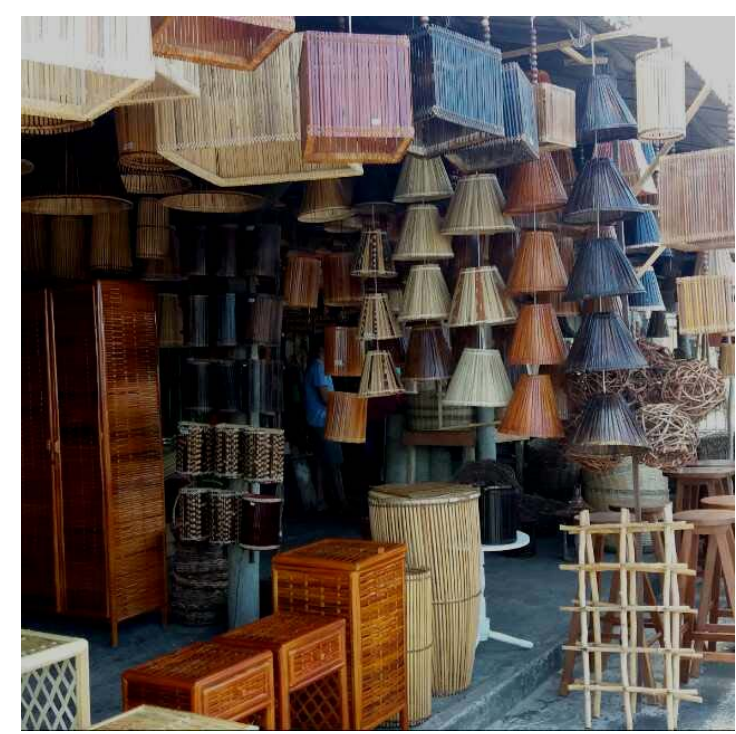

Figura 1 - Produtos - Artesanato do Dendê.

Fonte: Elaborado pelo autor, com base na pesquisa realizada.

1 Roda de conversa - metodologia participativa que articula conceitos psicossociais, onde seus participantes refletem acerca da sua relação com o mundo, com o trabalho e com o projeto de vida. (CRESWELL, 2010). 
Essa realidade vem preocupando os artesãos que vivem dessa atividade, pois a escassez de matéria-prima (Figura 2) para a fabricação dos artefatos pode provocar uma redução na produção, podendo causar um desequilíbrio no meio de subsistência, interferindo inclusive na vida dos terceiros que atuam nessa cadeia.

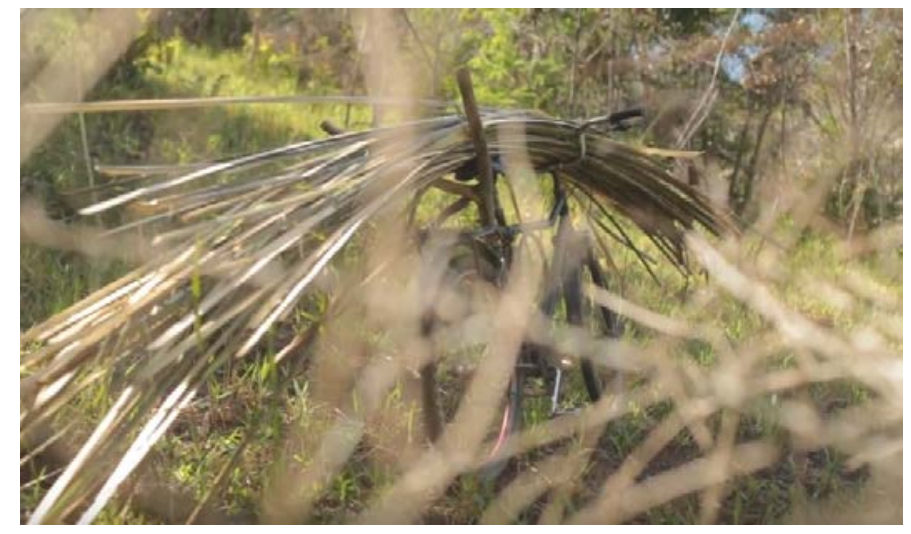

Figura 2 - Matéria-prima - Artesanato do Dendê.

Fonte: Elaborado pelo autor, com base na pesquisa realizada.

Existe uma grande preocupação com a continuidade do artesanato na região, sendo destacada a necessidade de cursos para formar novos artesãos. Relata-se inclusive, que há alguns anos, houve um esforço em formar novos artífices, mas que não foi adiante devido à irregularidade dessa capacitação, pois não havia uma formalização legal para o treinamento de jovens menores de 18 anos.

Diante das experiências vividas e expostas pela comunidade, o projeto exibe sua história para conhecimento da sociedade e comunidade local, bem como proporciona a visualização do valor material e imaterial do artesanato para o Estado, além da busca do fortalecimento da cultura do Artesanato do Dendê na região. Tratase de uma ação colaborativa entre diversos agentes no sentido de valorizar o trabalho desenvolvido e promover a sua continuidade amparada por instituições governamentais.

\subsection{Definição da proposta de estudo}

A estratégia metodológica utilizada neste trabalho foi uma ação colaborativa, com processo de decisão aberto, para chegar a um resultado benéfico para todos os integrantes dessa comunidade. Partindo deles, diante das entrevistas e rodas de conversas realizadas com o grupo, percebeu-se a necessidade de criar recursos para divulgação do trabalho dos artesãos, de modo que fosse valorizada a cultura do Artesanato do Dendê, pretendendo sensibilizar os jovens da comunidade em dar continuidade a este ofício.

No Quadro 1 são descritas as possibilidades de projeto, desenvolvidas durante uma reunião colaborativa, após estudo das situações percebidas junto à comunidade, em primeira visita ao local da comunidade. Foram elencadas as possibilidades e levantadas as dificuldades de execução do projeto; benefícios propostos à comunidade e recursos disponíveis, dentro do escopo de possibilidades da equipe, em execução do projeto. 
Quadro 1 - Levantamento de propostas de projeto.

\begin{tabular}{|c|c|c|c|}
\hline PROPOSTA DE PROJETO & DIFICULDADES & BENEFÍCIOS & RECURSOS NATURAIS \\
\hline $\begin{array}{l}\text { 1. Beneficiamento da } \\
\text { matéria-prima } \\
\text { (tecnológico e social) }\end{array}$ & $\begin{array}{l}\text { - Tempo disponível } \\
\text { para efetivação do } \\
\text { projeto. }\end{array}$ & $\begin{array}{l}\text { - Raspagem adequada } \\
\text { da palha } \\
\text { - Produtividade }\end{array}$ & $\begin{array}{l}\text { - Projeto Final de curso } \\
\text { - Prototipação }\end{array}$ \\
\hline $\begin{array}{l}\text { 2. Design de serviços } \\
\text { (fluxo de trabalho) }\end{array}$ & $\begin{array}{l}\text { - Reunir o grupo de } \\
\text { artesãos para coleta de } \\
\text { dados }\end{array}$ & $\begin{array}{l}\text { - Estruturação } \\
\text { planejada da atividade } \\
\text { produtiva do } \\
\text { artesanato }\end{array}$ & - Informações \\
\hline $\begin{array}{l}\text { 3. Construção de um } \\
\text { site/portal e- } \\
\text { commerce }\end{array}$ & $\begin{array}{l}\text { - Falta de união da } \\
\text { comunidade } \\
\text { - Dificuldade de } \\
\text { manutenção do portal }\end{array}$ & $\begin{array}{l}\text { - Divulgação dos seus } \\
\text { produtos além das } \\
\text { fronteiras físicas } \\
\text { - Possibilidade de } \\
\text { aumento de vendas e } \\
\text { comercialização para o } \\
\text { exterior }\end{array}$ & $\begin{array}{l}\text { - Informações } \\
\text { - Programação } \\
\text { - Conhecimento de } \\
\text { comercialização e- } \\
\text { commerce }\end{array}$ \\
\hline $\begin{array}{l}\text { 4. Ambientação e } \\
\text { identidade visual para } \\
\text { o novo espaço de } \\
\text { comercialização }\end{array}$ & $\begin{array}{l}\text { - Comunicação com a } \\
\text { Concessionária }\end{array}$ & $\begin{array}{l}\text { - Criação de uma } \\
\text { identidade aos } \\
\text { produtos }\end{array}$ & $\begin{array}{l}\text { - Acesso a plantas } \\
\text { deste "novo" espaço }\end{array}$ \\
\hline $\begin{array}{l}\text { 5. Planejamento de } \\
\text { aproveitamento do } \\
\text { resíduo - gestão do } \\
\text { resíduo }\end{array}$ & $\begin{array}{l}\text { - Mapeamento do } \\
\text { resíduo gerado pelo } \\
\text { artesanato tendo em } \\
\text { vista que a produção é } \\
\text { bastante segmentada }\end{array}$ & $\begin{array}{l}\text { - Gestão responsável } \\
\text { da matéria-prima } \\
\text { - Possibilidade de } \\
\text { geração de renda com } \\
\text { a comercialização do } \\
\text { resíduo }\end{array}$ & $\begin{array}{l}\text { - Informações técnicas } \\
\text { necessárias sobre a } \\
\text { matéria-prima } \\
\text { - Captação de } \\
\text { parceiros }\end{array}$ \\
\hline $\begin{array}{l}\text { 6. Vídeo documentário } \\
\text { da "vida" dos artesãos }\end{array}$ & $\begin{array}{l}\text { - Envolvimento da } \\
\text { comunidade com a } \\
\text { produção do vídeo } \\
\text { (aceitação e ser } \\
\text { filmado) }\end{array}$ & $\begin{array}{l}\text { - Resgate da memória } \\
\text { cultural da } \\
\text { comunidade } \\
\text { - Possibilidade de } \\
\text { manutenção da cultura } \\
\text { material e imaterial do } \\
\text { artesanato } \\
\text { - Construção de uma } \\
\text { "ferramenta" de } \\
\text { diálogo com a indústria } \\
\text { local e governo }\end{array}$ & $\begin{array}{l}\text { - Equipamentos de } \\
\text { filmagem (máquinas } \\
\text { filmadoras, microfone, } \\
\text { iluminação etc.) }\end{array}$ \\
\hline
\end{tabular}

Fonte: Elaborado pelos autores, com base na pesquisa realizada.

É importante salientar que este projeto faz parte da proposta de trabalho de uma disciplina de pós-graduação, que possui um prazo de conclusão limitado a 4 meses. Após esta etapa foram descartadas as possibilidades de projeto que demandariam um tempo de execução maior, principalmente as relacionadas ao tempo disponível para execução do projeto e aos benefícios propostos à comunidade. Deste modo foram descartados os projetos do portal e-commerce e de identidade visual/ambientação do "novo" espaço.

Como sequência, foi discutida a pertinência dos demais projetos com os professores orientadores. Quanto à proposta de se desenvolver um equipamento que auxiliasse no beneficiamento da matéria-prima, discutiu-se o possível desequilíbrio financeiro que geraria na comunidade, tendo em vista que muitas pessoas sobrevivem 
da terceirização deste beneficiamento. Quanto ao projeto de design de serviço discutiu-se a interferência no atual processo produtivo, discutiu-se que a comunidade já possui um sistema produtivo implantado e que, o projeto de serviços, poderia provocar ruído nesta estrutura de produção. Ainda se enfatizou que muitos projetos teriam dificuldades de serem implantados e aceitos pela comunidade em função da falta de união dos artesãos. Percebeu-se, na visita ao local, que os artesãos, em muitos momentos, mostram-se desmotivados e pouco coesos na produção do artesanato.

Deste modo, o projeto mais adequado, diante da escassez de tempo e recursos, é a produção de um vídeo documentário, na tentativa de elevar a estima dos artesãos. $O$ documentário também servirá como uma memória registrada da cultura do artesanato, conceituando-se como uma ferramenta de comunicação entre as novas gerações de artesãos, iniciativa privada e governamental. Assim, ficou definido o desenvolvimento do projeto do vídeo-documentário do Artesanato do Dendê, com plena aceitação dos representantes da comunidade, que se manifestaram durante uma reunião para tomada de decisões.

\subsection{Execução do projeto}

Com a proposta de explorar a realidade local, propôs-se filmar a representação parcial e subjetiva da vida dos artesãos, desde a extração da matéria-prima até a produção do artesanato, através de um eixo problematizador - 0 que é o Artesanato do Dendê para você? Com esta pergunta de partida, coletou-se depoimentos que partilham a visão dos artesãos para eles mesmos e para toda comunidade que se subsidia do artesanato, principalmente aos futuros artesãos, considerando, sob uma perspectiva social, o coletivo e a sua relevância.

Nesta perspectiva, o vídeo documentário expõe o objeto social Artesanato do Dendê, sob o propósito de possibilitar indagações e ou reflexões, sobre a sua continuidade, fundamentando o título do vídeo - "Artesanato do Dendê: para onde vai? ". Um questionamento para o futuro do artesanato e da comunidade, bem como um questionamento sobre o aspecto físico de mudanças que, atualmente, a comunidade vem sofrendo.

Para a execução das filmagens foram destinados dois dias com envolvimento de toda equipe de projeto, técnicos para filmagem e toda a comunidade; e a utilização de equipamentos profissionais de alta resolução. Utilizou-se como locação o "mato", onde é extraída a matéria-prima (Figura 03), e o local de venda do artesanato.

A edição do vídeo se deu após análise de todo material filmado, com a decupagem do mesmo e a definição das falas e cenas importantes para o contexto almejado. Para a culminância do projeto, o documentário foi apresentado à comunidade em um evento planejado para, também, elevar a estima e o prestígio dos artesãos. A comunidade foi convidada a assistir o documentário em uma sala de cinema. 


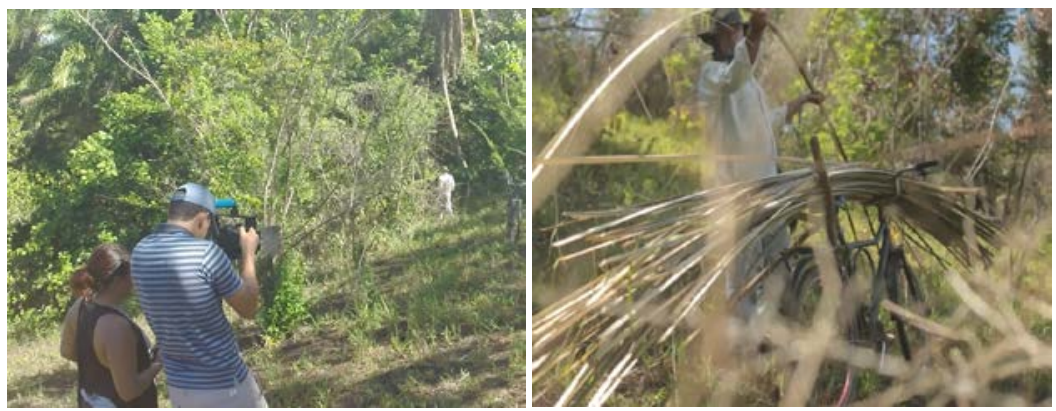

Figura 03 - Local onde é extraída a matéria-prima - Artesanato do Dendê.

Fonte: Elaborado pelos autores, com base na pesquisa realizada.

Iniciamos o evento (Figura 04) com uma palestra sobre economia criativa, exibimos o vídeo documentário e encerramento com a entrega da mídia digital do vídeo-documentário para os líderes e representantes de cada família envolvida no processo.

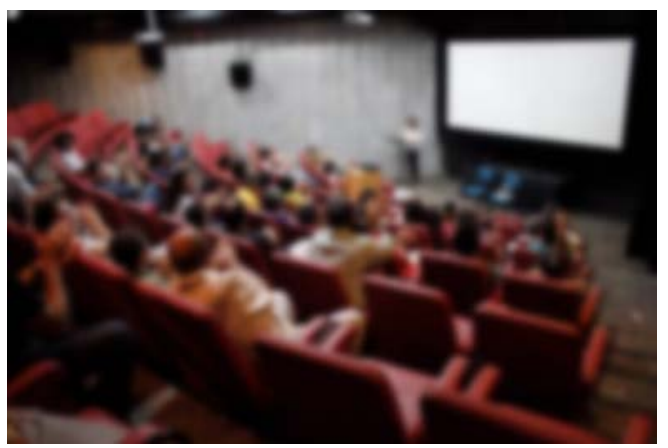

Figura 04 - Evento para exibição do vídeo-documentário

Fonte: Elaborado pelos autores, com base na pesquisa realizada.

\section{CONCLUSÃO}

Considerando que o principal objetivo do design seja encontrar soluções para problemas complexos buscando alternativas e meios satisfatórios de execução, Souza e Factum (2009, p. 126) afirmam que "[...] espera-se que os designers migrem de um domínio exclusivo de prospecção de objetos materiais para o desenvolvimento de soluções para sistemas humanos e ambientes naturais [...]". Nesta busca, Souza e Factum $(2009$, p. 126) reforçam ainda que "[...] o resultado do design pode promover novos valores que, de forma abrangente, influenciam o modo de vida das pessoas e as formas de obtenção de satisfação". Em vista disso, o design pode contribuir com as inovações sociais, promovendo a interação do caso em estudo com uma nova realidade e um olhar observador mais sensível às experiências vividas.

Para a equipe envolvida no projeto, a proposta proporcionou uma experiência de estar à frente dessa realidade, percebendo o ambiente de outra forma e sendo capazes de gerar mudanças com soluções adequadas para determinadas situações, intensificando a busca contínua por novos conhecimentos e integrando os demais estudos já adquiridos no programa acadêmico.

Para os orientadores, pela possibilidade de discutir design e inovação social sob a perspectiva do desenvolvimento colaborativo, fez com que o olhar da equipe se 
tornasse mais reflexivo, promovendo novas abordagens do design, bem como a contribuição para a comunidade, agregando valor ao Artesanato do Dendê.

Conclui-se que o objetivo proposto foi alcançado, com a criação do instrumento de diálogo com a sociedade civil e governo, para incentivo à continuidade e fortalecimento da cultura do artesanato da palha de dendê na região, com a produção de um documentário, realizado de modo colaborativo e entregue em mídia digital para os líderes e representantes de cada família envolvida no processo.

Foi possível promover uma proposta de design para inovação social na comunidade, por meio de um vídeo-documentário, promovendo a autoestima e valorização dos artesãos. Ressaltamos que o projeto desenvolvido pode ser compartilhado e reproduzido em outros grupos de artesãos que identificam a necessidade de visibilidade do seu fazer, proporcionando uma oportunidade de vivenciar experiências orientadas pelo design e pelo processo colaborativo de construção de um bem maior, a valorização do artesanato.

\section{REFERÊNCIAS}

BAXTER, Mike. Projeto de Produto: guia prático para o desenvolvimento de novos produtos. São Paulo: Edgard Blücher, 2001.

BECKMAN, S; BARRY, M. Innovation as a Learning Process: Embedding Design Thinking. In California Management Review, v. 50, n. 1, Fall 2007, pp.25-56.

BORGES, A. Saber artesanal. Janeiro/2012. São Paulo: Revista Brasileiros, p. 94-97. Entrevista concedida a Marcelo Rezende.

BORGES, A. Mostra Design, inovação e sustentabilidade - Design, innovation and sustainability. 2010. p. 40-217. Disponível em: http://docplayer.com.br/2987254Brasil-design-inovacao-e-sustentabilidade-brazil-design-innovation-andsustainability.html Acesso em: 23/04/2016

CRESWELL, J. W. Projeto de pesquisa: métodos qualitativo, quantitativo e misto. 3.ed. Porto Alegre: Artmed/Bookman, 2010.

DESERTI, A. Possible trajectories for design consulting. Politécnico de Milano, 2011, 5 slides: color

MANZINI, Ezio. Design para a inovação social e sustentabilidade: comunidades criativas, organizações colaborativas e novas redes projetuais. Rio de Janeiro: Epapers, 2008.

MANZINI, E. Making things happen: social innovation and design. In Design Issues, v. 30, n. 1, Winter 2014, pp. 57-66.

MARGOLIN, Victor; MARGOLIN, Sylvia. Um "modelo social" de design: questões de prática e pesquisa. Revista Design em Foco, julho-dezembro, 2004/vol. I, número 001. Universidade do Estado da Bahia, Salvador/Brasil, pp. 43-48. Disponível em:

$<$ http://designparasustentabilidade.files.wordpress.com/2010/06/um-modelosocialde-design.pdf>. Acesso em 23/04/2016.

MARTINS, I. P. Uma reflexão à luz das teorias do imaginário para pensar outras/novas formas de ensinar design. VII Seminário de Pesquisa em Educação na Região Sul. 
Pesquisa em Educação e Inserção Social. Anais: Itajaí-SC: Universidade Federal de Pelotas, 2008, 12p.

MORAES, D. E. Dijon. Metaprojeto: o design do design. São Paulo, Editora Edgard Blücher, 2010.

MULGAN, G. Social Innovation: what it is, why it matters, how it can be accelerated. London, Basingstoke Press, 2007.

ROZENFELD, Henrique et. al. Gestão de desenvolvimento de produtos. São Paulo: Saraiva, 2006.

SOUZA, P.; FACTUM, A. O papel do design na promoção de Comércio Justo e Solidário. In: Cultura Visual, n. 12, outubro/2009, Salvador: EDUFBA, p. 125-136.

The Young Foundation. Social Innovation Overview: A deliverable of the project: "The theoretical, empirical and policy foundations for building social innovation in Europe". In (TEPSIE) European Commission - 7th Framework Programme, Brussels: European Commission, DG Research.

VACARO, Baba. Fazer brasileiro. Casa Claudia Luxo, São Paulo, julho/2013. Disponível em: http://casa.abril.com.br/materia/adelia-borges-artesanato-design. Acesso em: 18/05/2016. 